\title{
Lo posible, ya y bien
}

\author{
Rodrigo Fierro-Benítez
}

Debo agradecerle a la vida. He tenido la suerte, el privilegio infrecuente, de haberme dedicado a trabajar en áreas que me tocaban hondamente y que aludían a mi circunstancia, en el sentido que Ortega y Gasset le daba al término.

Por el lado materno formo parte de una familia campesina de la provincia del Tungurahua, en los Andes ecuatorianos. Desde niño fui acumulando impresiones sobre las condiciones en las que se debatía la existencia del labriego de mi comarca. Los bocios monstruosos y los casos de deficiencia mental profunda que veía golpeaban como verdaderos puñetazos mi embrionaria vocación de médico y de investigador. Es la razón, no me cabe duda, de haber optado por la endocrinología como especialidad, habiendo sido decisivas en mi formación las dotes ejemplares de mis dos maestros: el español Gregorio Marañón y el estadounidense John B. Stanbury. Del primero, su humanismo; del segundo, su rigor metodológico.

Formo parte, además, de aquella generación de endocrinólogos latinoamericanos que cursaba estudios en el exterior cuando se iniciaba la utilización de los isótopos radiactivos en el diagnóstico y tratamiento de las enfermedades de la glándula tiroides. Era el inicio de la era moderna y las fronteras adquirían un alcance insospechado. Tal coyuntura nos llevó a realizar cursos complementarios de Medicina Nuclear con un empeño que superaba nuestra deficiente formación en ciencias básicas.

A poco de retornar a mi país fui llamado por la Escuela Politécnica Nacional para que dirigiera el recién creado Departamento de Aplicaciones Biomédicas del Instituto de Ciencias Nucleares. Poco tiempo después fui el primer titular, por concurso, de la Cátedra de Endocrinología de la Facultad de Ciencias Médicas de la Universidad Central. Tales instituciones se constituyeron en mi piso y en mi techo para cuanto me proponía. Sin esos apoyos mis afanes se habrían reducido a puros sueños, situación nada infrecuente en algunos de nuestros países.

Es así como, con recursos limitadísimos pero utilizando las tecnologías de punta para aquel entonces, iniciamos nuestras investigaciones sobre los que hoy se conocen por trastornos por deficiencia de yodo, de los cuales en ese momento apenas se habían identificado el bocio endémico y el cretinismo endémico, y este último sin definición precisa a inicios de los años sesenta del siglo pasado.

Nuestras investigaciones vinieron a sumarse a las que se efectuaban en otros países y fueron demostrando que los trastornos por deficiencia de yodo constituían un mayúsculo problema de salud pública cuyas implicaciones iban mucho más allá de lo que se suponía. En revistas especializadas y en reuniones académicas fuimos presentando nuestros hallazgos a consideración de la comunidad científica y de los organismos internacionales.

Uno de los días más gloriosos, digámoslo así, que tengo en la memoria fue aquel de 1962: los Institutos Nacionales de Salud (NIH) de los Estados Unidos me comunicaban que un proyecto de investigación que habíamos presentado había sido aprobado para recibir financiamiento. Fue nuestro primer grant y los dólares comenzaron a llovernos. Igual respuesta nos dieron otras instituciones, como la Organización Panamericana de la Salud (OPS), por más de treinta años ininterrumpidos.

Pese a que ya se conocían los efectos devastadores de la deficiencia de yodo, en la mayoría de los países afectados no se daba la voluntad política que 
requerían los programas nacionales de yodación de la sal. Infructuosos resultaban los esfuerzos de las comunidades médicas locales y de las agencias internacionales de salud pública.

En cuanto al espacio que aludía a mi circunstancia, el estado de deterioro biológico al que habían llegado las grandes masas campesinas de Ecuador, Perú y Bolivia, al cual contribuían en gran medida los trastornos por deficiencia de yodo, no se compadecía con su pasado prehispánico. Aquel pueblo que se presentaba enfermo y biológicamente debilitado había sido protagonista de una gran epopeya: la adaptación del hombre a un hábitat bravo y difícil. Había sido el creador de una de las grandes civilizaciones que registra la historia. A su tenacidad e inteligente observación de la naturaleza el mundo le debía las mayores aportaciones que hubiese hecho cualquier pueblo a la alimentación humana: la papa, el maíz y la quinua.

En el caso concreto de Ecuador, el conocimiento empírico llevó al serrano prehispánico a preferir y consumir las sales provenientes de "las salinas yodíferas de los Andes", como las denominó Boussingault a comienzos del siglo XIX. Pocos años antes el yodo había sido identificado y ya se sabía de sus propiedades para curar los bocios. "Al uso continuo de esta sal deben los habitantes de esta provincia el privilegio de carecer del coto", según opinión precisa del mismo Boussingault.

Preferida por el español la sal que provenía de la costa (carente de yodo), de aspecto cristalino y similar a la que utilizaba en su tierra de origen, las sales yodadas de los Andes, conocidas por "sales de indios" y de color amarillento y sabor amargo, fueron cayendo en desuso hasta casi desaparecer. A la malnutrición calórico-energética que llegó a afectar a todo el campesinado del altiplano andino se sumó la deficiencia de yodo y los trastornos por deficiencia de este nutriente "explosionaron" en el siglo XVIII, según expresión de Greenwald.

Pese a todos los argumentos y motivaciones, muchos países de todos los continentes no tenían programas de yodación de la sal. Ante tal situación y como alternativa, pues no podíamos quedarnos cruzados de brazos, en febrero de 1966 fuimos los primeros en corregir la carencia de yodo por medio del uso a escala comunitaria del aceite yodado de depósito. Nuestros resultados fueron avalados por la OPS y aquel método fue utilizado en numerosos países de América, África y Asia. Es la razón para que participara, en calidad de Consultor Principal del Consejo Internacional para el Control de los Desórdenes por Deficiencia de Yodo (ICCIDD, siglas correspondientes a International Council for the Control of Iodine Deficiency Disorders), en programas para la utilización de aceite yodado que se pusieron en ejecución en Perú, Camerún y la República Popular China.

Fue tan solo en 1984 que el Gobierno ecuatoriano decidió iniciar, como política de Estado, el programa de yodación de la sal para el control de los trastornos por deficiencia de yodo. Hasta la fecha, algo más de $95 \%$ de la sal que se consume contiene concetraciones apropiadas de yodo y un porcentaje similar de la población consume sal yodada. Los trastornos por deficiencia de yodo van desapareciendo del panorama sanitario nacional.

Tales resultados nos llevaron a la certidumbre de que habíamos escogido el camino correcto. En un país como el mío, al igual que en casi todos los del mundo en desarrollo, donde hay limitaciones de todo género, lo posible era lo mejor. Pudimos habernos empeñado también en organizar un programa nacional para el tamizaje (screening) del hipotiroidismo neonatal, que es más común en las poblaciones con deficiencia de yodo. Dicho programa requiere de un sistema de servicios de salud altamente estructurado y eficiente y que cubra todo el territorio nacional. Un sistema tal es un objetivo a largo plazo y requerirá transformaciones profundas. 
Yodar la sal era lo posible y, por ende, era lo mejor. Por esa ruta hemos trajinado, sabiendo bien que corregir la malnutrición calórico-energética era lo más importante, aunque requería de esas transformaciones sociales, políticas y económicas que algún día se darán. Entre tanto nos correspondía hacer lo que era posible, y ya y bien.

Hicimos lo mismo en un esfuerzo por corregir las deficiencias alimentarias de hierro y vitamina A. En Ecuador, altos porcentajes de mujeres embarazadas y niños menores de dos años presentaban anemia ferropénica. En las áreas más empobrecidas la deficiencia de vitamina A era una realidad. En el país se habían hecho estudios que no admitían dudas. Se trataba de dos graves problemas de salud pública.

En 1995 se dio la voluntad política para controlarlos y para tal propósito se contaba con recursos prestados por el Banco Mundial que no habían sido utilizados. El Ministro de Salud de entonces, Alfredo Palacio, vino a solicitarme que me hiciera cargo de la dirección de un Comité Nacional de Micronutrientes que estaba por crearse. Tal comité sería el responsable de que se continuara apropiadamente el programa de yodación de la sal y de que se iniciaran programas contra las deficiencias de hierro y vitamina A. Me di por aludido, ante tal deferencia, y acepté un desafío que valía la pena. Abandoné algunas de mis actividades habituales. Me puse manos a la obra con el máximo apoyo político que me ofrecía el Ministro Palacio.

Cuando me hice cargo de la dirección de aquel comité se contaba con un proyecto que teníamos que convertir en un programa concreto. El Ministerio de Salud contaba, además, con un grupo de especialistas de muy buen nivel que se había mantenido a la espera de que lo "soltaran". Casi todos habían sido mis alumnos en la Facultad de Medicina, conocían mi temperamento y se hallaban dispuestos a ofrecerme todo su concurso.

Por otra parte, bioquímicos del Minsiterio de Salud y de la Universidad Central habían montado técnicas de laboratorio de relativa complejidad para hacer las determinaciones de retinol y otras que nos serían necesarias.

El Comité Nacional de Micronutrientes en poco tiempo se constituyó en un verdadero equipo de trabajo que actuaba como tal, pues nos habíamos puesto de acuerdo en ciertos extremos: ya no cabían más diagnósticos; había que pasar a la acción. Los conocimientos que teníamos sobre el hierro y la vitamina A eran suficientes como para actuar con criterios propios cuando fuera del caso; nos hallábamos familiarizados con los trabajos de campo y los asuntos relacionados con la comunicación no revestían mayores complejidades. Algunas decisiones que tomó el Comité llegaron a lo anecdótico: en los pósteres y trípticos no aparecerían niños rubios; las figuras humanas tendrían las características fisonómicas de los habitantes de la Sierra y de la Costa y, como consecuencia, no tendrían pinta de "gringos". Cuando a las comunidades se las convocara por perifoneo para la suplementación con vitamina A no se utilizaría una música de fondo tan abrumadoramente triste como lo es la ecuatoriana por lo general; más bien, para la Sierra escogimos "el toro barroso", una tonadilla de embestida, de fuerza, de brío, y para la Costa no nos quedó otro recurso que utilizar "el venado" por su sabor tropical.

Es así como el equipo ecuatoriano se presentaba ante los representantes de los organismos extranjeros e internacionales que habían manifestado su interés en apoyar nuestros programas. El mensaje era claro: nosotros, los ecuatorianos, dirigiríamos tales programas, pero la colaboración extranjera e internacional nos era necesaria y sería bienvenida. Su reacción fue en extremo positiva y nos sentimos potenciados. En contados casos se dieron disparidades de criterio, algunas de fondo, como cuando decidimos que la suplementación de hierro se hiciera los miércoles y domingos, y no diariamente, desde luego que con buenas razones. Nos opusimos a nuevos sondeos de opinión debido a los 
gastos que significaban y al tiempo que exigían, y por haberse demostrado que eran innecesarios en la práctica. Texto en mano, uno de los funcionarios extranjeros se empeñaba en perfecciones que no se compadecían con la realidad de nuestro país.

Así fue como logramos conformar un gran equipo en el que los nativos y foráneos compartían compromisos y responsabilidades, una noble pasión, un noble empeño. Debo hacer especial mención a la colaboración calificada, entusiasta y fraternal que nos brindó Carlos Samayoa, Asesor en Nutrición de la Representación de la OPS/OMS en Ecuador.

El Programa ecuatoriano para la corrección de las deficiencias alimentarias de hierro y vitamina A materializó en agosto de 1996. Dicho Programa fue considerado por el Fondo de las Naciones Unidas para la Infancia (UNICEF) como un modelo para otros países.

Hasta la fecha, en Ecuador la corrección de las deficiencias de micronutrientes es una política de Estado. Contamos con sal yodada y fluorada, con harina de trigo enriquecida con hierro, ácido fólico y vitaminas del complejo B. La suplementación con hierro y vitamina A es una práctica corriente en las unidades operativas del Ministerio de Salud y las organizaciones vinculadas con él. El monitoreo y la evaluación de los programas se realizan con regularidad.

En materia de nutrición creemos haber hecho lo mejor, es decir, lo que es posible, y ya y bien. He contribuido a ello. Debo, pues, agradecerle a la vida: mis empeños se hicieron realidad en la medida de lo posible.

\section{CENTENARIO DE LA ORGANIZACIÓN PANAMERICANA DE LA SALUD}

Reflexiones de ex-funcionarios de la OPS

Francisco López Antuñano, ex-Director, Enfermedades Transmisibles:

"Nadie puede tener una vida plena si no tiene salud. Entonces la salud es el principal recurso de la vida misma... creo que una de las misiones más importantes de la Organización es justamente difundir el valor de la salud y hacer que la aprecie todo ser humano. La salud es el mayor recurso que tienen los seres humanos para desarrollar su vida como un todo."

Myron Wegman, ex-Secretario-General:

"No fue hasta recién comenzado el siglo XX que logramos entender la relación de las bacterias con las enfermedades infecciosas. El desarrollo de la Organización fue paralelo a esto durante años e hizo posible poner el progreso científico al servicio de las personas, de un modo que habría sido impensable cien años atrás. El avance, desde la concentración en las enfermedades transmisibles hasta el fortalecimiento de la salud y el bienestar, ha sido constante y la capacidad de la OPS de mantener inalterable su meta de mejorar la salud de todos, es, a mi parecer, un triunfo para todos."

Abraham Drobny, Oficial Médico 1953-1978:

"Cuando yo ingresé a la Organización era alrededor de 1902 y ninguno de nosotros pensó que iba a lograr vivir hasta que la Organización tuviera 100 años. A mí me parecen trascendentales la forma en que la Organización ha crecido y la influencia que ha tenido en estos cien años en el desarrollo de los servicios de salud y de todas las actividades de salud de los países." 